\title{
Geometric Shape
}

National Cancer Institute

\section{Source}

National Cancer Institute. Geometric Shape. NCI Thesaurus. Code C101119.

The spatial outline of an object as described by the configuration of straight or curved lines. 